\title{
Biofiltration of a Styrene/Acetone Vapor Mixture in Two Reactor Types under Conditions of Styrene Overloading
}

\author{
Lubos Zapotocky ${ }^{1}$, Martin Halecky², Tomas Vanek $^{2}$, Jan Paca ${ }^{2 *}$, Evguenii Kozliak ${ }^{3}$, Kim \\ Jones $^{4}$ and Carlos Ricardo Soccol ${ }^{5}$ \\ ${ }^{I}$ Dekonta; Stehelceves - Czech Republic. ${ }^{2}$ Department of Biotechnology; Institute of Chemical Technology; Prague - \\ Czech Republic. ${ }^{3}$ Department of Chemistry; University of North Dakota; Grand Forks - USA. ${ }^{4}$ South Texas \\ Environmental Institute; Texas A\&M University-Kingsville; Kingsville - USA. ${ }^{5}$ Departamento de Engenharia de \\ Bioprocessos e Biotecnologia; Universidade Federal do Paraná; Paraná - Brasil
}

\begin{abstract}
This aim of study was to compare the performance of a biofilter $(B F)$ and trickle bed reactor (TBR) under increased styrene loading with a constant acetone load, $2 \mathrm{gd} / \mathrm{m}^{3} / \mathrm{h}$. At styrene loading rates up to $30 \mathrm{gd} / \mathrm{m}^{3} / \mathrm{h}$, the BF showed higher styrene removal than TBR. However, the BF efficiency started to drop beyond this threshold loading and could never reach steady state, whereas the TBR continued to yield a 50\% styrene removal. The acetone removal remained constant (93-98\%) in both the reactors at any styrene loading. Once the overloading was lifted, the BF recovered within 26 min, whereas the TBR efficiency bounced back only to 95\%, gradually returning to complete removal only in $10 \mathrm{~h}$.
\end{abstract}

Key words: biofiltration, styrene, acetone, vapor mixtures, two reactors

\section{INTRODUCTION}

Removal of readily biodegradable paint booth solvents is one of the potential applications of biofiltration, an air purification technique based on the use of immobilized aerobic bacteria (Devinny et al. 1999). A number of studies have been conducted on this application, using both common bioreactor types, i.e., biofilters (BFs) with low water usage (Li and Moe 2005) and their opposite, trickle-bed bioreactors (TBRs), which may be called in situ bioscrubbers (Webster et al. 1999). These studies laid a sound foundation for designing the bioreactors featuring sufficiently high residence times (low air flow rates) (Bastos et al. 2003; Chang and Lu 2003; Atoche and Moe 2004; Mathur and Majumder 2008) and using appropriate mineral feeds and packing materials for various substrates in different reactors (Song et al. 2003; Li and Moe 2005).

However, two significant barriers to success exist for a wide use of biofiltration for the treatment paint booth off-gases. The first challenge in achieving a steady bioreactor performance is that the substrates are often mixtures of several solvents; thus, whenever the pollutant biodegradation is rate limiting, substrate interactions become significant. Furthermore, paint booth mixtures usually consist of both polar (e.g., esters, ketones) and non-polar solvents (most often, aromatic hydrocarbons). In this case of two "foreign" groups of substrates, different enzyme systems are required for the catabolism of two kinds of pollutants. As a result, negative substrate interactions may lead to pronounced effects, i.e., a decline of the removal efficiency of one substrate

*Author for correspondence: Jan.Paca@ vscht.cz 
when the loading by the other component increases (McGrath et al. 1999; Lu et al. 2002; Alvarez-Hornos et al. 2011).

The second challenge, which may further enhance the first one, is the uneven application of different solvents in time. As a result, the system is never at steady state in terms of vapor composition, with inherent oscillations of substrate concentrations, periodic reversal of polar vs. non-polar substrate composition and, as the worst-case scenario, frequent overloading of system's biodegradation capacity by one of the solvents. Besides causing a breakthrough of a given pollutant, this feature may lead to a shutdown of other pollutants' removal. Moreover, overloading stresses may trigger longlasting effects, such as a temporary loss of the biofilm activity even when the system returns to normal pollutant loads. These effects may differ in two common practical biofiltration systems, because both the excess and shortage of water, characteristic for TBRs and BFs, respectively, may alter the overloading threshold depending on whether the overloading pollutant is watersoluble. Practitioners, thus, need to make informed decisions on which reactor to use to treat specific pollutant mixtures.

Detailed studies were undertaken on the system modeling of biofiltration of a mixture of aromatic hydrocarbons and polar solvents using both bioreactor types. Since it is difficult to compare the multiple previous studies conducted with different inocula, under varied operational conditions and in different reactors, they were run in parallel as BF and a similar-size TBR sharing the same inoculum. This unified all of these factors, with only one variable subject to change, the major substrate loading, while keeping the loading of the second, minor substrate low and constant. In the first of these studies, polar solvents (ketones and esters) were the minor component whereas the loading of the major component, aromatic hydrocarbons, was gradually increased until overloading, then monitoring the long-term effects of overloading (Paca et al. 2010). In the second study, a reciprocal loading pattern was applied, i.e., with a constant low amount of the same polar solvents under increasing loading by the same aromatic hydrocarbons (Paca et al. 2012a).

These two studies documented a number of substrate interactions, thus necessitating a further reduction in the system's complexity. Another study addressed the biofiltration of a mixture of just two components, styrene (minor component) and acetone (major component), with a gradual increase in the loading by the latter (Paca et al. 2012b). To complement that work, the current study was designed to monitor the application of a reciprocal loading pattern. Namely, the objective of the current study was to compare the performance parameters of two different bioreactors under stepwise increased loading by styrene at pseudo steady state. Following the eventual long-term overloading, the reactor dynamic response was monitored upon its return to the starting loading rates.

\section{MATERIALS AND METHODS}

\section{Reactor design, microbial inoculum and system operation}

The schematics of both the reactors are shown in Figures 1 and 2. Detailed descriptions of two bench-scale bioreactors used in this study were provided in previous publication (Paca et al. 2012b). The trickle bed reactor (TBR, Fig. 1) height was $1.70 \mathrm{~m}$ with an internal diameter of $0.15 \mathrm{~m}$. Pall rings made of hydrophilized polypropylene were used as a packing material; the bed height was $1.0 \mathrm{~m}$. The Pall rings' dimensions were $15 \times 15 \times 1 \mathrm{~mm}$, with a specific void volume of 0.862 , specific surface area of 350 $\mathrm{m}^{2} / \mathrm{m}^{3}$ and bulk density of $120 \mathrm{~kg} / \mathrm{m}^{3}$.

The biofilter (BF, Fig. 2) was made of glass with a height of $1.0 \mathrm{~m}$ and internal diameter of $100 \mathrm{~mm}$. The packing material was Poraver (crushed recycled glass) with a grain size of $8-16 \mathrm{~mm}$ and porosity of 0.44 . The same enrichment culture [Sphingobacterium multivorum $\left(\mathrm{G}^{-}\right.$rods), Comamonas testosteroni ( $\mathrm{G}^{-}$rods), Pseudomonas putida ( $\mathrm{G}^{-}$rods) and Bacillus cereus $\left(\mathrm{G}^{+}\right.$rods) all being primary styrene and acetone degraders] was immobilized in both the reactors and then used in previous study conducted with the same substrates (Paca et al. 2012b). Similar to this previous study, the reactors were operated in a concurrent airwater down-flow mode at the same empty bed retention time of $53 \mathrm{~s}$.

The same dilute mineral medium of the following composition was used in both reactors (per liter):

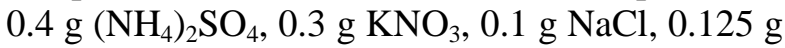
$\mathrm{K}_{2} \mathrm{HPO}_{4}, 0.085 \mathrm{~g} \mathrm{KH}_{2} \mathrm{PO}_{4}, 0.34 \mathrm{~g} \mathrm{MgCl}_{2} 6 \mathrm{H}_{2} \mathrm{O}$, $0.7 \mathrm{mg} \mathrm{MnCl}$, $1.3 \mathrm{mg} \mathrm{CaCl}_{2}, 0.6 \mathrm{mg} \mathrm{FeSO}_{4}, 1.7$ mg $\mathrm{Na}_{2} \mathrm{MoO}_{4}$. The contents of phosphates and 
nitrate were lower than those common for standard mineral media to suppress an excessive biomass growth. $\mathrm{pH}$ of the circulating aqueous medium was maintained at 7.0 using a pH-stat; the hydraulic loading circulation rate was $2.242 \mathrm{~m} / \mathrm{h}^{1}$.

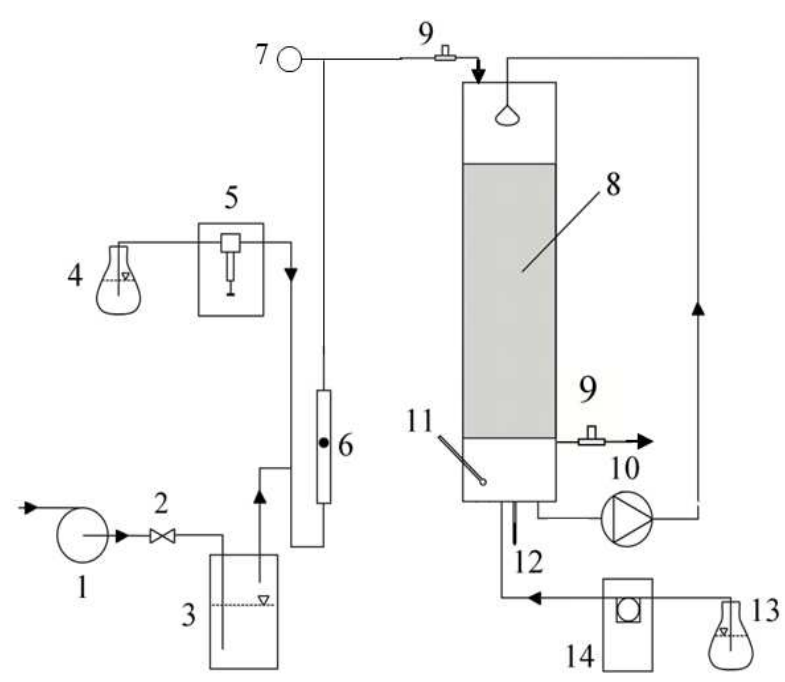

Figure 1 - Schematic of the trickle bed reactor set-up. 1- blower, 2 - needle valve for air-flow rate control, 3 - humidifier, 4 - vessel with pollutant, 5 - syringe pump, 6 - flow meter, 7 - manometer, 8 - packing, 9 - sampling ports, 10 - membrane pump, $11-\mathrm{pH}$ electrode, 12 - thermometer, $13-\mathrm{NaOH}$ solution, 14 - peristaltic pump.

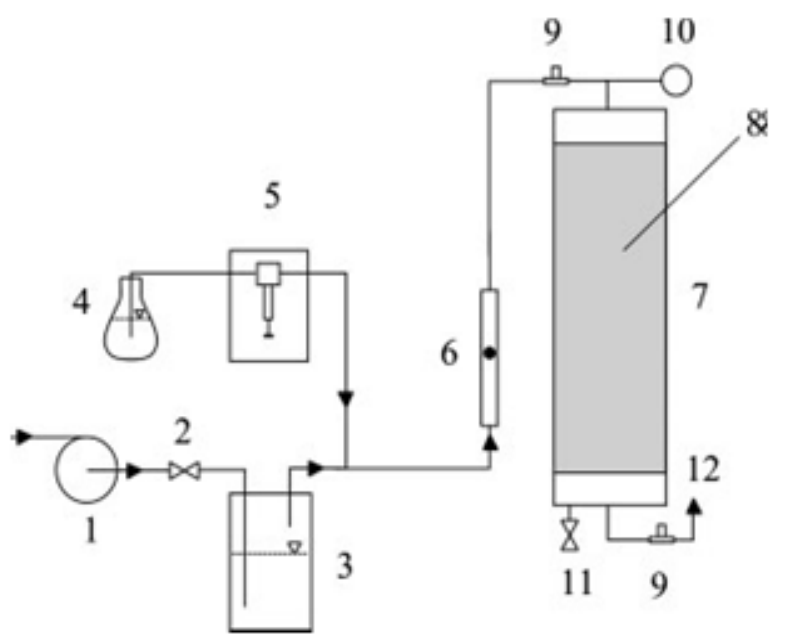

Figure 2 - Schematic of the biofilter set-up. 1 - blower, 2 - needle valve for flow rate control, 3 humidification vessel, 4 - vessel with pollutant, 5 - syringe pump, 6 - flow meter, 7 - biofilter, 8 - packing, 9 - sampling ports, 10 - manometer, 11 - valve for leachate, 12 gas outlet.

\section{Chromatographic analyses}

Styrene and acetone in the gas phase were determined using an Agilent $6890 \mathrm{~N}$ gas chromatograph (Agilent Technologies, Inc., Santa Clara, CA, USA), equipped with a 30-m ultra alloy-5 (5\% phenylmethylsilicone) capillary column featuring an inner diameter of $0.53 \mathrm{~mm}$ and film thickness of $1.5 \mu \mathrm{m}$ (Quadrex Corp., UA5 - 30V - 1.5 F, New Haven, CT). Ultra-high purity argon was a carrier gas at a flow rate of 5.0 $\mathrm{mL} / \mathrm{min}^{1}$. Detection was carried out using a flame ionization detector (FID). Temperatures of 80 and $250^{\circ} \mathrm{C}$ were set for the column and detector, respectively. The flow rates of ultra-high purity hydrogen and breathing quality air were 28 and $315 \mathrm{~mL} / \mathrm{min}^{1}$, respectively.

The acetone concentration in the TBR recirculation medium was analyzed using an HPLC system (DeltaChrom, Watrex Ltd., Prague, Czech Republic) with a $250 \mathrm{~mm} \times 4 \mathrm{~mm}$ Nucleosil, 120-5 C18 column (Watrex Ltd., Prague, Czech Republic). A mobile phase of methanol/water (50:50) was applied at a flow rate of $1.0 \mathrm{~mL} / \mathrm{min}^{1}$. Peaks were detected with a diode array detector (Model UV 6000 LP, Thermo Separation Products, Inc., San Jose, CA, USA) by measuring the absorbance at $268 \mathrm{~nm}$.

\section{Loading procedure}

The details of bioreactor operation were the same as described by Paca et al. (2012b). Since the bioreactors had been adapted to the styrene/acetone mixture in the previous study, no adaptation/start-up procedures were required. The starting acetone concentration of $50 \mathrm{mg} / \mathrm{m}^{3}$ corresponding to a loading of $2.2 \mathrm{~g}_{\mathrm{c}} / \mathrm{m}^{3} / \mathrm{h}$ was applied in both the reactors. The starting styrene concentration was $60 \mathrm{mg} / \mathrm{m}^{3}$, corresponding to a loading of $2.5 \mathrm{gc} / \mathrm{m}^{3} / \mathrm{h}$. The inlet concentration of acetone remained constant throughout the entire period of experimentation, whereas the styrene concentration gradually increased up to 550 $\mathrm{mg} / \mathrm{m}^{3}$. The empty bed residence time (EBRT) in both the reactors was maintained at $53 \mathrm{~s}$; the operational temperature was $22 \pm 1^{\circ} \mathrm{C}$. The system recovery tests were conducted in both the reactors once the biofilter was overloaded by styrene to such an extent that an uncontrollable decline of $\mathrm{RE}_{\mathrm{STY}}$ was observed. Namely, the styrene inlet concentration was returned back to its starting concentration of $60 \mathrm{mg} / \mathrm{m}^{3}$. The resulting changes in substrate removal were then monitored in time until the new steady state values were reached. 


\section{Calculations}

The removal efficiency (RE), elimination capacity (EC), organic load (OL) and empty bed residence time were calculated using standard definitions of these operation and performance parameters, as described by Paca et al. (2012b).

\section{RESULTS AND DISCUSSION}

\section{Pollutant removal upon increasing styrene loading}

The loading scheme (operational parameters) and the impact of increasing styrene loading on styrene and acetone RE (performance parameters) are shown in Figures 3A-B, respectively. Increasing the styrene loading caused virtually no effect on the acetone removal in both the reactors throughout the entire experimentation period. $\mathrm{RE}_{\mathrm{AC}}$ remained above $90 \%$ even under the system overloading by styrene (Fig. 3B). However, a complete acetone removal, with an RE of $100 \%$, was never observed regardless of the styrene load, despite of the low $\mathrm{OL}_{\mathrm{AC}}$ value.

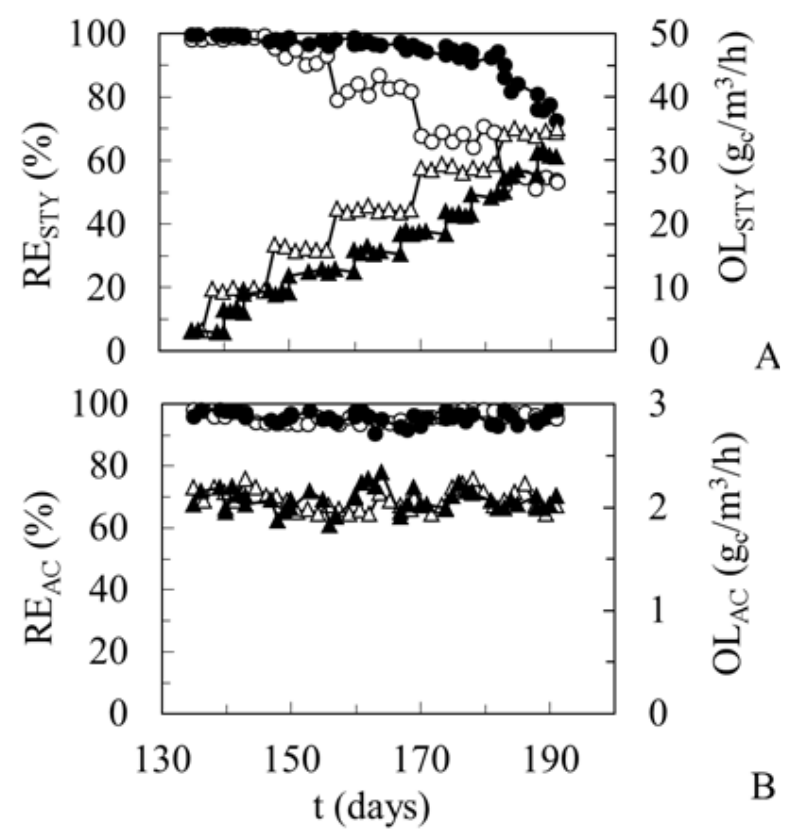

Figure 3 - Loading rates and their impact on RE of styrene (A) and acetone (B) in the TBR and BF. OL-TBR $(\Delta)$, OL-BF $(\boldsymbol{\Delta})$, RE$\operatorname{TBR}(\circ), \operatorname{RE}-\mathrm{BF}(\bullet)$.

By contrast, the styrene removal was negatively impacted by a moderate increase of its own loading, this effect being more pronounced in the
TBR compared to BF (Fig. 3A). Once the $\mathrm{OL}_{\mathrm{STY}}$ exceeded $15 \mathrm{~g}_{\mathrm{c}} / \mathrm{m}^{3} / \mathrm{h}$, the $\mathrm{RE}_{\mathrm{STY}}$ in the TBR dropped below $90 \%$, whereas in the $\mathrm{BF}$, the styrene degradation remained near-complete (Fig. 4A). This pattern continued at higher $\mathrm{OL}_{\mathrm{STY}}$. However, above the threshold $\mathrm{OL}_{\mathrm{STY}}$ of 30 $\mathrm{g}_{\mathrm{c}} / \mathrm{m}^{3} / \mathrm{h}$, the TBR continued to exhibit a poor yet steady styrene removal of near 50\%; in contrast, the $\mathrm{BF}$ performance dropped gradually having failed to reach steady state. Thus, the further increase of styrene loading had to be halted.

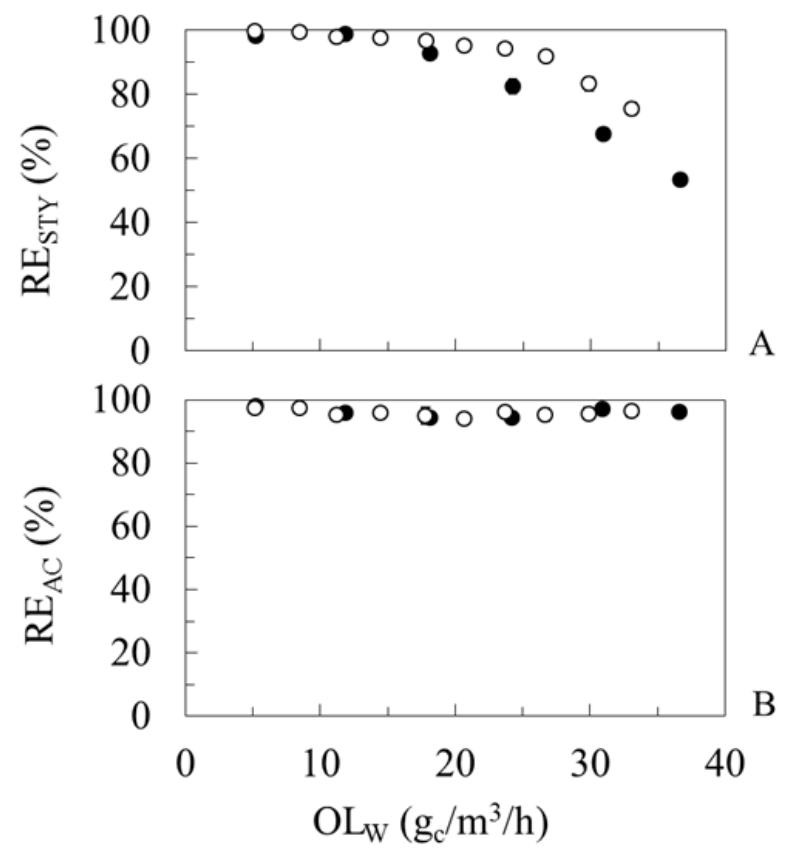

Figure 4 - Impact of styrene overloading on the removal efficiency of styrene (A) and acetone (B) in the TBR $(\bullet)$ and BF (O). Only the steady state values were used.

\section{Pollutant interactions and rate limiting step}

Figures $4 \mathrm{~A}$ and $\mathrm{B}$ show the removal efficiencies of styrene and acetone vs. $\mathrm{OL}_{\mathrm{W}}$, respectively. The observed consistently high (>93\%) $\mathrm{RE}_{\mathrm{AC}}$, being unaffected by either higher styrene loading or even its overloading (Fig. 4B) indicated that the two substrates' catabolic enzymes were different and independent, just as expected. In previous similar study with multiple aromatic and polar compounds, this feature was not observed (Paca et al. 2010). In particular, the acetone removal was negatively affected by increasing loads of toluene and xylenes in the presence of esters and ketones, apparently due to multiple substrate interactions (Paca et al. 2012a). 
Table 1 shows the comparison of $\mathrm{BF}$ and TBR performance at the same substrate loadings, conducted at the upper threshold value for BF, as explained above. Evidently, the biofilter showed better performance in styrene removal up to this upper threshold value, with similar acetone removal efficiencies. This trend is well visible in Figure 5, which is an EC vs. OL plot. This showed that under steady state conditions, the biofilter outperformed the TBR, particularly at higher loadings, as long as $\mathrm{OL}_{\mathrm{STY}}$ was below an upper threshold value of $30 \mathrm{~g}_{\mathrm{c}} / \mathrm{m}^{3} / \mathrm{h}$.

Table 1 - Comparison of performance parameters achieved under steady state at $\mathrm{OL}_{\mathrm{W}}=33 \mathrm{~g}_{\mathrm{c}} / \mathrm{m}^{3} / \mathrm{h}$.

\begin{tabular}{lccccc}
\hline & $\mathbf{R E}_{\text {STY }}$ & $\mathbf{R E}$ & $\mathbf{R E}_{\mathbf{A C}}$ & $\mathbf{E C}_{\mathbf{w}}$ & $\boldsymbol{\Delta} \mathbf{p}$ \\
\cline { 2 - 6 } & & $(\%)$ & & $\left(\mathrm{g}_{\mathrm{c}} / \mathrm{m}^{3} / \mathrm{h}\right)$ & $\left(\mathrm{mm} \mathrm{H}_{2} \mathrm{O}\right)$ \\
\hline TBR & 61 & 97 & 65 & 22 & $2-24$ \\
$\mathrm{BF}$ & 73 & 94 & 74 & 25 & $5-37$ \\
\hline
\end{tabular}

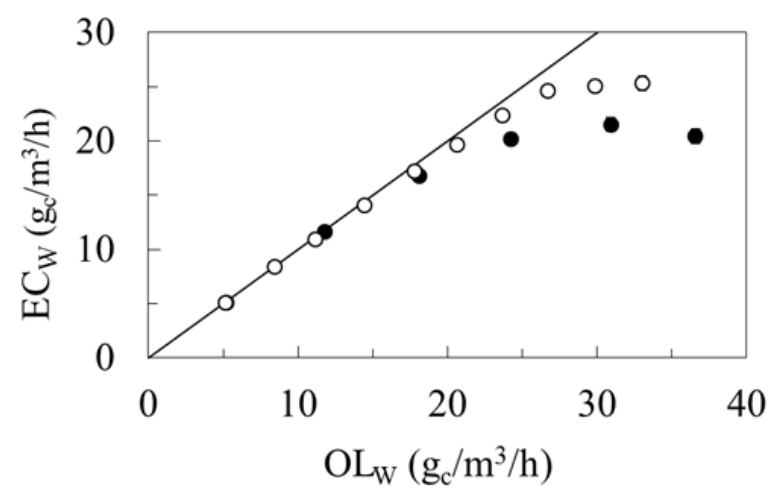

Figure 5 - Comparison of the overall elimination capacity in the TBR (•) and BF (०). Only the steady state values were used.

A higher styrene removal efficiency observed in the BF compared to TBR provided the evidence for mass transfer being rate-limiting, at least for styrene removal. This difference could be explained by a smaller packing particle size in the $\mathrm{BF}$ leading to a larger effective mass transfer surface area, as shown by Paca et al. (2012a). Corroborating this observation, Mathur and Majumder (2008), as well as Paca et al. (2009), showed that the styrene elimination capacity could be increased by an order of magnitude by using a packing made of activated carbon, which was an effective styrene absorbent facilitating its mass transfer. This effect could be enhanced by a lower effective aqueous layer thickness in the BF due to a limited water supply.

Acetone mass transfer through the aqueous medium is higher compared to styrene because of the two orders of magnitude difference between the corresponding Henry's law coefficients (Staudinger and Roberts 2001; Yaffe et al. 2003). Preferential utilization of more water-soluble ketones in the presence of aromatics was, thus observed in previous studies (Cai et al. 2006; Paca et al. 2012a). However, consistently <100\% acetone removal observed in the current study in both the reactors while styrene was removed completely at similar (low) concentrations indicated that the biochemical acetone degradation fluxes could be comparable to those of its mass transfer. Such a dual nature of the rate-limiting step of acetone removal corroborated the modeling results obtained in a similar system by Gerrard et al. (2010), the modeling ascertained the zero order on acetone but yielded comparable goodness of fit for mass transfer and reaction limited assumptions.

Chang and Lu (2003) and Atoche and Moe (2004) reported the values of $\mathrm{OL}_{90 \%}$ for overloading by aromatics (toluene), 68 (BF) and 125 (TBR) $\mathrm{g}_{\mathrm{c}} / \mathrm{m}^{3} / \mathrm{h}$, respectively, which ed the threshold value of $30 \mathrm{~g}_{\mathrm{c}} / \mathrm{m}^{3} / \mathrm{h}$ observed in this study. Apparently, due to mass transfer limitations the selection of the most effective packing material becomes a crucial factor for the removal of hydrocarbons. Mathur and Majumder (2008) reported the $\mathrm{OL}_{90 \%}$ $=125 \mathrm{~g}_{\mathrm{d}} / \mathrm{m}^{3} / \mathrm{h}$ for a mixture of toluene, xylenes and ketones using coal as a packing material to improve mass transfer.

\section{Dynamic tests upon overloading}

The dynamic recovery tests, conducted upon a step-drop of $\mathrm{OL}_{\mathrm{STY}}$ after overloading, showed that the system remained to be robust, despite the prior long-term overloading by styrene. The new pseudo-steady-state $>90 \%$ efficiency values were achieved in just 26 min and 56 min in the BF and TBR, respectively (Fig. 6). Yet, the biofilter still outperformed the TBR. The RE $E_{S T Y}$ in the TBR continued to climb slowly, reaching the near$100 \%$ original value, i.e., equal to that observed at the start of experiments, only in $10 \mathrm{~h}$. The $\mathrm{RE}_{\mathrm{AC}}$, once the styrene overloading was lifted, immediately increased in both the reactors, from 98 to $100 \%$ in the BF and from 95 to $98 \%$ in the TBR. Subsequently, the $\mathrm{RE}_{\mathrm{AC}}$ gradually dropped 
back to 98 and $90-95 \%$, respectively, exhibiting oscillations in the TBR.

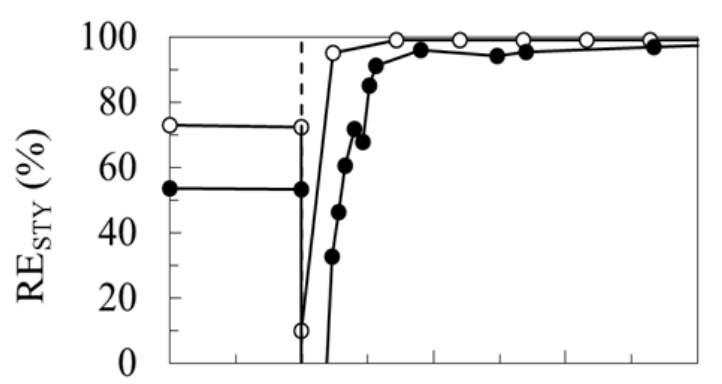

A

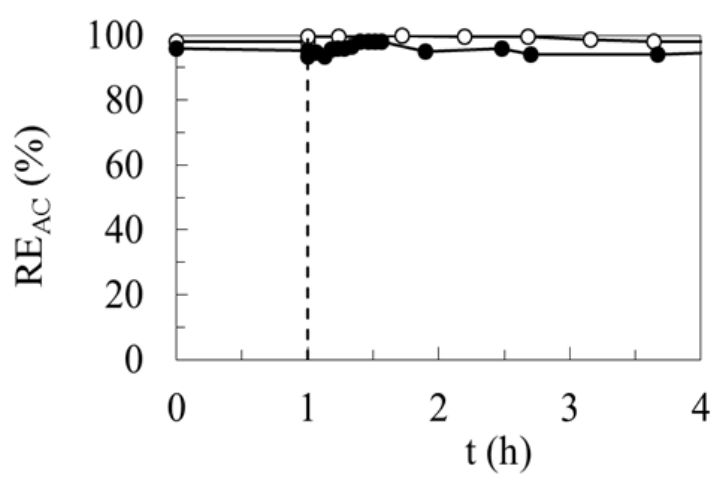

Figure 6 - The dynamic responses of styrene (A) and acetone (B) after a step-drop of styrene overloading to the original loading rates in the TBR $(\bullet)$ and BF $(\circ)$.

In contrast to steady-state conditions, acetone was removed either completely or, at least, with a greater efficiency for the first few hours after lifting the overloading by styrene (Fig. 6). Perhaps, a sudden transition from overloading to a much lower styrene loading rate resulted in an immediate removal of dissolved styrene from circulating water; so acetone could be metabolized faster as the only remaining growth substrate. Lifted substrate interactions and greater oxygen availability could also boost acetone oxidation under such conditions. A similar feature was observed in previous study for butyl acetate, once the overloading by toluene and xylene was lifted (Paca et al. 2010).

\section{CONCLUSION}

At steady state, the BF should be preferred over TBR when hydrophobic substrates, such as styrene, are to be treated. However, the BF was more sensitive to overloading by styrene with a drastic loss of activity whereas the TBR retained
$50 \%$ removal efficiency even under severe overloading. Dynamic recovery tests showed that the system remained robust after styrene overloading.

\section{ACKNOWLEDGEMENTS}

The work was financially supported by the Ministry of Education of the Czech Republic, Project KONTAKT II LH13073 and by the Czech Technology Agency, Project TA03020395.

\section{REFERENCES}

Alvarez-Hornos FJ, Gabaldón C, Martínez-Soria V, Marzal P, Penya-Roja JM, Izquierdo M. Long-term performance of peat biofilters treating ethyl acetate, toluene, and its mixture in air. Biotechnol Bioeng. 2007; 96: 651-60.

Atoche JC, Moe WM. Treatment of MEK and toluene mixtures in biofilters: Effect of operating strategy on performance during transient loading. Biotechnol Bioeng. 2004; 86: 468-481.

Bastos FSC, Castro PML, Jorge RF. Biological treatment of a contaminated gaseous emission from a paint and varnish plant - from laboratory studies to pilot-scale operation. J Chem Technol Biotechnol. 2003; 78: 1201-1207.

Cai Z, Kim D, Sorial GA, Saikaly P, Zein MM, Oerther DB. Performance and microbial diversity of a tricklebed air biofilter under interchanging contaminants. Eng Life Sci. 2006; 6: 37-42.

Chang K, Lu C. Biofiltration of toluene and acetone mixtures by a trickle-bed air biofilter. World $J$ Microbiol Biotechnol. 2003; 19: 791-798.

Devinny JS, Deshusses MA, Webster TS. Biofiltration for Air Pollution Control. Boca Raton, Lewis Publishers. 1999.

Gerrard AM, Havranek J, Novak V, Halecky M, Jones K, Soccol CR, Paca J. Modelling the steady state and dynamics of a biotrickling filter treating styrene and acetone in air. Braz Arch Biol Technol. 2010; 53: 1225-1234.

Li C, Moe WM. Activated carbon load equalization of discontinuously generated acetone and toluene mixtures treated by biofiltration. Environ Sci Technol. 2005; 39: 2349-2356.

Lu C, Lin M-R, Wey I. Removal of acetone and methylacetate mixtures from waste gases by a tricklebed air biofilter. Environ Technol. 2002; 23: 243252.

Mathur AK, Majumder CB. Biofiltration and kinetic aspects of a biotrickling filter for the removal of paint solvent mixture laden air stream. J Hazard Mater. 2008; 152: 1027-1036. 
McGrath MS, Nieuwland JC, van Lith C. Case study: Biofiltration of styrene and butylacetate at a dashboard manufacturer. Environ Prog. 1999; 18: 197-204.

Paca J, Halecky M, Kozliak E. Styrene biofiltration using two packing materials with different adsorption properties. Environ Eng Sci. 2009; 26: 195-208.

Paca J, Halecky M, Misiaczek O, Kim J, Kozliak E, Sobotka M. Biofiltration of paint solvent mixtures in two reactor types: Overloading by hydrophobic components. J Ind Microbiol Biotechnol. 2010; 37: 1263-1270.

Paca J, Halecky M, Misiaczek O, Kozliak E, Kim J. Biofiltration of paint solvent mixtures in two reactor types: Overloading by polar components. J Environ Sci Health Part A-Toxic/Hazard Subst Environ Eng. 2012a; 47: 1936-1945.

Paca J, Halecky M, Novak V, Jones K, Kozliak E. Biofiltration of a styrene/acetone vapor mixture in two reactor types under conditions of acetone overloading. J Chem Technol Biotechnol. 2012b; 87: 772-777.
Song JH, Kinney KA, John P. Influence of nitrogen supply and substrate interactions on the removal of paint VOC mixtures in a hybrid bioreactor. Environ Prog. 2003; 22: 137-144.

Staudinger J, Roberts PV. A critical compilation of Henry 's law constant temperature dependence relations for organic compounds in dilute aqueous solutions. Chemosphere. 2001; 44: 561-576.

Webster TS, Togna AP, Guarini WJ, McKnight L. Application of a biological trickling filter reactor to treat volatile organic compound emission from a spray paint booth operation. Met Finish. 1999; 97: 20-26.

Yaffe D, Cohen Y, Espinosa G, Arenas A, Giralt F. A fuzzy ARTMAP-based quantitative structureproperty relationship (QSPR) for the Henry 's Law constant of organic compounds. J Chem Inf Comput Sci. 2003; 43: 85-112. 